Document downloaded from:

http://hdl.handle.net/10251/65062

This paper must be cited as:

Bermúdez, V.; Serrano Cruz, JR.; Piqueras, P.; Campos, D. (2015). Analysis of the influence of pre-DPF water injection technique on pollutants emission. Energy. 89:778-792. doi:10.1016/j.energy.2015.05.142.

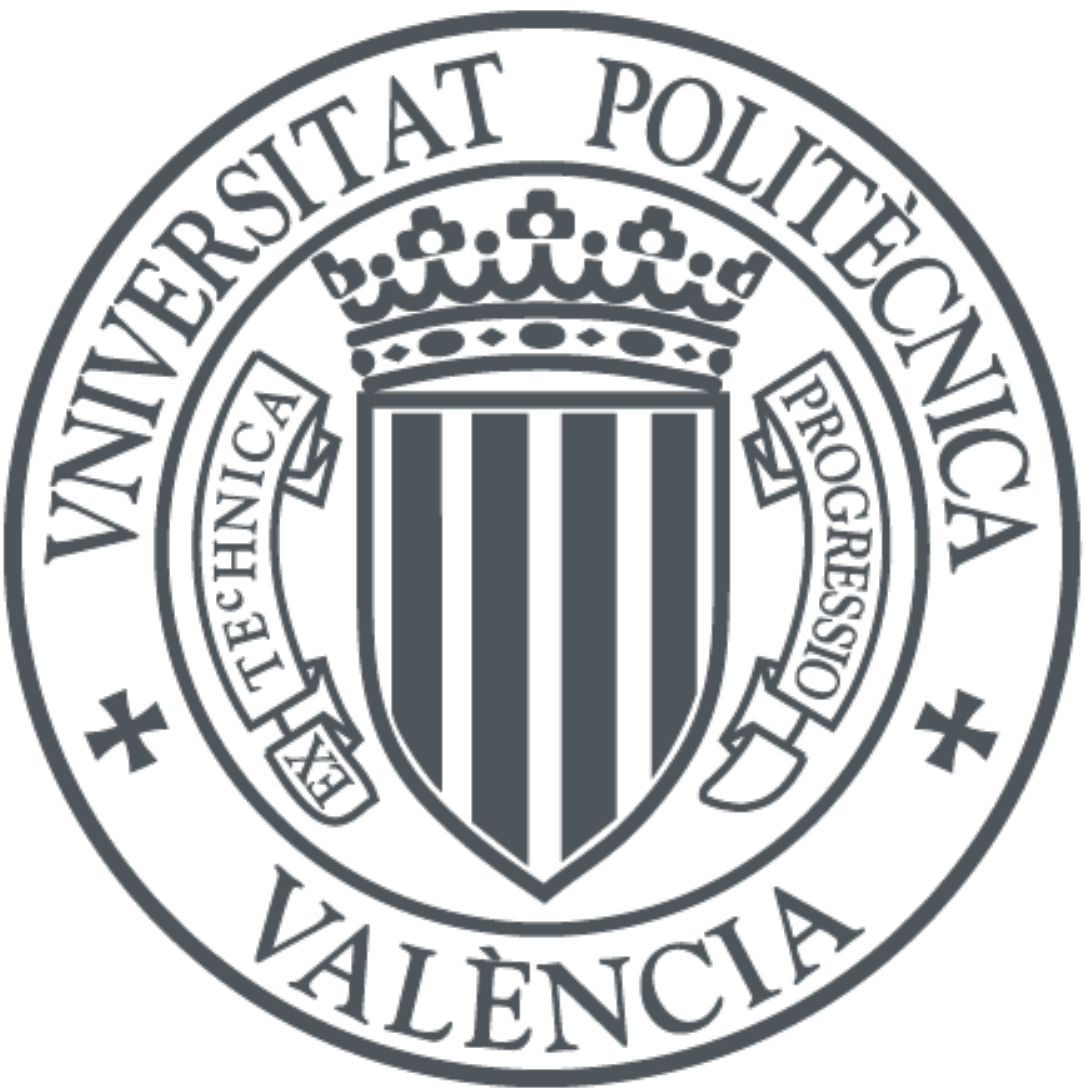

The final publication is available at

http://dx.doi.org/10.1016/j.energy.2015.05.142

Copyright Elsevier

Additional Information 


\title{
Analysis of the influence of pre-DPF water injection technique on pollutants emission
}

\author{
Vicente Bermúdez *, José Ramón Serrano, Pedro Piqueras, Daniel Campos \\ Universitat Politècnica de València, CMT-Motores Térmicos, Camino de Vera s/n, 46022 Valencia, Spain.
}

\begin{abstract}
The pressure drop across diesel particulate filters directly affects the exhaust back-pressure and the fuel economy of internal combustion engines. Such a pressure drop is related to the soot trapped inside the DPF so that the exhaust back-pressure increases as the soot mass loading does. Consequently regeneration strategies are required in order to remove the soot collected at the DPF. However, these processes usually involves additional fuel consumption.

Considering this context, new design approaches and control techniques to reduce the exhaust back-pressure dependence on DPF soot loading are arising. One technique is based on the injection of water at the DPF inlet to get a new redistribution of the particulate matter and a reduction of the DPF pressure drop. The possibility to keep constant the exhaust back-pressure by consecutive pre-DPF water injection events provides better control on tailpipe particle emissions. The aim of this paper is to establish a comprehensive analysis of the pollutant emission and particle behavior during pre-DPF water injection events. The DPF filtration efficiency and the particle size distribution are also analysed after performing a DPF loading test with pre-DPF water injection events. Results have shown a negligible transient particle emission during the pre-DPF water injection event and that there are not effects on overall filtration efficiency.
\end{abstract}

Keywords: Diesel engine, diesel particulate filter, pre-DPF water injection, particle emission, gaseous emission

\section{Introduction}

Diesel engines have very high thermal efficiency what means lower fuel consumption and lower carbon dioxide $\left(\mathrm{CO}_{2}\right)$ emissions than equivalent gasoline engines [1]. During the last decades, diesel engines have undergone an 4 increase in their sales, reaching and overtaking gasoline engines production. However, nitrogen oxides (NOx) and particulate matter (PM) emitted by diesel engines are usually related to health [2] and environmental problems [3], such as asthma sicknesses and air pollution [4].

Innovative technologies and the development of new systems are needed to achieve the mitigation of environmental pollution caused by compression ignition engines. In the last decade, different strategies have been studied and

\footnotetext{
*V. Bermúdez. CMT-Motores Térmicos, Universitat Politècnica de València, Camino de Vera s/n, 46022 Valencia, Spain. Phone: +34 963877650 Fax: +34 963877659 e-mail: bermudez@ mot.upv.es
} 
developed as solutions to reduce pollutant diesel engine tailpipe emissions: exhaust gas recirculation (EGR) [5], piezoactuated direct-acting injectors [6], improvements in the fuel-air mixture process [7], optimized engine control [8], heat management solutions [9], etc. These improvements contribute to exhaust emissions reduction, but are just insufficient to fulfil the current pollutant regulations. Due to this fact, the use of aftertreatment systems in the exhaust line to abate carbon monoxide (CO), unburned hydrocarbons (HC), NOx and PM is necessary [10]. In the case of PM, diesel particulate filters (DPFs), and mainly wall-flow DPFs, were identified decades ago as the most effective system for soot emission reduction. However, these aftertreatment systems have been adopted in commercial applications during last years with the coming into force of stringent regulations focused on soot mass emitted [11]. In this sense, the use of wall-flow DPFs has allow reducing soot mass emission around 99\% [12].

A wall-flow DPF is a monolithic structure of axial parallel channels. The channels are alternatively plugged at each end and the exhaust flow is forced to pass across the porous wall from the inlet to the outlet channels. This flow path makes the particulate matter to be filtered and accumulated in the porous wall until the regeneration takes place. Inside the DPF, the trapped particulate matter is firstly collected inside the porous walls and then on its surface forming the soot cake, whose thickness increases as the soot is filtrated [13]. After long-term use this process highly affects the engine fuel economy because of the increasing engine back-pressure [14]. Previous studies have developed models to predict the DPF pressure drop as a function of the flow conditions and the porous medium properties [15]. Particularly, it is established how the permeability, porosity, and pore size evolves from clean conditions as the soot loading increases, affecting the pressure drop [16] and the filtration process [17].

Since the pressure drop increases as the soot cake grows up [18], the DPF needs to be actively regenerated by burning off the trapped soot [19]. Active regeneration based on fuel late injection during the expansion stroke is the most usual strategy. The post-injected fuel is burned out in the diesel oxidation catalyst (DOC) giving as a result an increase of the DPF gas inlet temperature. It favours the oxidation of the soot particles collected in the DPF [20]. Recently several authors have proposed alternatives to increase the ability of passive regeneration [21] but just without engine performance penalty [22]. They have shown excellent filtration efficiency specially for the very small particle size, which are the most harmfull for human healths [23], by placing the DPF upstream the turbine

In a recent study, a novel technique presented by Serrano et al. [24] driven to control the DPF pressure drop independently of the soot loading has been described. The technique is based in the use pre-DPF water injection events during normal operation of the DPF [25]. It allows keeping constant the pressure drop over time without influence of the soot loading. The pre-DPF water injection redistributes the soot collected at the inlet channels providing a pressure drop reduction and consequently reducing the exhaust back-pressure [24]. The use of consecutive water injection events provides benefits to engine fuel economy and also higher flexibility for DPF regeneration and maintenance, which become only dependent on soot or ash mass loading disrupting any relation with pressure drop.

The aim of this paper is to describe the behaviour of the pollutant emission released to the atmosphere during the transient application of the pre-DPF water injection and the overall DPF operation when is subjected to this technique over time. The work covers the analysis of the gaseous emission and particle behavior during the pre-DPF 
water injection event besides the assessment of the total particle emission, particle size distribution (PSD) and hence filtration efficiency during DPF loading tests with pre-DPF water injection. Finally, additional tests under steadystate operating conditions have been performed after soot loading tests carried out with baseline DPF operation and applying the pre-DPF water injection technique. The results give further information about the mode in filtration efficiency (FE) and, finally, on the particle emission during passive regeneration processes.

\section{Experimental setup}

In this section a general description of the main characteristics of the engine, the main properties of the used fuel are provided and a detailed description of the different equipments for engine operation and emissions characterisation are provided.

\subsection{Test bench facilities}

The pre-DPF water injection technique has been tested in a 4-cylinder, turbocharged, high-speed direct-injection (HSDI) diesel engine for passenger car application. The main specifications of the engine are detailed in Table 1. The engine accounts for a common rail injection systems, short route exhaust gas recirculation (SR-EGR) and an aftertreatment system to fulfill EURO 4 standards. The aftertreatment system is composed of a close-coupled diesel oxidation catalyst (pre-DOC) placed at the turbine outlet, a DOC and a wall-flow DPF. The main characteristics of the diesel particulate filter are reported in Table 2.

The fuel used in the tests was ultra-low sulfur diesel (ULSD), according to National standards. The detailed specifications of the fuel properties are described in Table 3.

The engine was installed in a completelly instrumented test cell equipped with all the auxiliary facilities required for its operation and control. This test cell was designed with the criteria detailed by Plint and Martyr [26]. The engine was connected to a dynamometric brake SCHENCK®DINAS LI250, which allows instant speed and torque engine control. In order to ensure possible modifications of any engine parameter, the electronic control unit (ECU) is fully open and the engine settings maps can be recalibrated with the ETAS $R I N C A$ software. The test bench was equipped with thermocouples and pressure sensors along the air path. In the case of the DPF, the pressure drop was measured by placing two piezorresistive transducers in the inlet and outlet cones. The gas temperature was measured with K-type thermocouples placed also in the canning cones. The instrumentation also includes sensors to measure the main magnitudes defining the engine, such as air mass flow, fuel mass flow, engine speed, engine torque and turbocharger speed.

\subsection{Emissions measurement equipment}

Four different systems were used in this study for particle and pollutant emissions measurement. These systems and its placement is schematically shown in Figure 1. The tailpipe gaseous pollutant emissions were monitored with an HORIBA@Mexa 6000 F-TIR analyzer [27], which was placed downstream of the DPF. 
Concerning particle number emission, on one hand, a TSI®Engine Exhaust Particle Sizer (EEPS) spectrometer was used for particle concentration measurement. It provides a fast response in particle concentration changes [28] being able to measure the PSD within the range 5.6 to $560 \mathrm{~nm}$ with a frequency up to $1 \mathrm{~Hz}$. The system was connected to a pneumatic valve system allowing the alternative measurement upstream and downstream of the DPF under steadystate conditions to provide the DPF filtration efficiency.

The dilution system employed in this study to condition the exhaust gas sample at the EEPS was a Dekati®FPS4000 [29]. This system dilutes the sample in two stages. The methodology used to measure the particle size distribution under steady-state and transient operating conditions [30] is sketeched in Figure 2. It consists of a dilution at constant temperature in the primary diluter, which is a porous tube (PTD). This first dilution allows reducing the volatile mass concentration. Subsequently an ejector (ED) acts as secondary diluter reducing further the volatile mass concentration (but avoiding nucleation) at the same time that the sample temperature is decreased.

On the other hand, the characterisation of the particulate matter emission is complemented measuring the exhaust gas opacity with the partial-flow opacimeter AVL®439 [31], which is capable to measure opacity under transient operating conditions. In addition, a smokemeter AVL®415S [32] was eventually used in order to provide paper filter results corresponding to the soot emissions produced during the pre-DPF water injection event.

Despite the continuous development and enhancement of exhaust gas analysers, there are relevant difficulties associated with the emission measurement that have to be taken into account when transient tests are performed. The main problem is that particle and gas analysers usually have longer response time than the engine dynamics and the rest of transducers. Therefore, pollutant emission signals are slightly delayed in comparison with the rest of the engine parameters. Since analysers measure particle concentration or gaseous concentration, the exhaust mass flow must be also determined to calculate the instantaneous mass of emitted pollutants. Therefore, the synchronization between the exhaust mass flow and the measurement of the exhaust gas analysers becomes critical. To overcome these issues, the synchronizing method proposed by Broatch et al. [33] was applied in this study.

\section{Test schedule}

Different tests were performed in order to assess the characterisation of pollutant emissions when the pre-DPF water injection technique is applied. The methodology for the analysis of the experimental results is based on the comparison between tests carried out with baseline DPF operation and then repeated applying the pre-DPF water injection technique.

For this purpose, the concept of "Test-set" was used. Figure 3 shows the called "Test-set" for every DPF operation condition. Every "Test-set" is composed of the following steps:

- DPF soot loading tests under steady-state operating conditions at $2500 \mathrm{rpm}, 28 \%$ engine load and EGR rate of $16 \%$. The objective is to keep the engine parameters constant and at the same time analyze the influence of consecutive pre-DPF water injection events on the DPF loading process and their effects on the particle behavior 
and gaseous emissions. The soot loading test was performed up to $30 \mathrm{~g}(11 \mathrm{~g} / \mathrm{l})$. In the case of the use of the pre-DPF water injection, water began to be injected from $9 \mathrm{~g}(3.3 \mathrm{~g} / \mathrm{l})$ and injections were repeated as many times as required to keep the maximum pressure drop below the baseline value (corresponding to $9 \mathrm{~g}$ of soot loading) until $30 \mathrm{~g}(11 \mathrm{~g} / \mathrm{l})$ of soot loading was again achieved [24]. An example of this process is shown in Figure 4, which evidence the potential for pressure drop control of water injection.

- In order to assess different engine operating regions, steady-state operating conditions were tested after loading the DPF up to $30 \mathrm{~g}$. Table 4 shows the three low load steady-state operating points assessed that were selected to evaluate the DPF filtration efficiency as a function of the PSD and the strategy for the DPF operation.

Additionally, three high-load steady-state operating points were tested to analyse the DPF passive regeneration process when pre-DPF water injection is applied comparing against DPF baseline operation. The main characteristics of these operating points are shown in Table 5.

\subsection{Methodology to test steady-state operating conditions}

A by-pass system with two electrovalves was placed upstream of the aftertreatment system. This by-pass system is shown in the pictures of Figure 1. It was considered to know the soot mass loading in the DPF at the beginning of every test. During engine thermal stabilisation the valve in the aftertreatment branch is completely closed and the bypass valve controls the tailpipe exhaust pressure. Engine backpressure is set to the same order of magnitude than the value imposed by the aftertreatment. When the engine is operating at steady-state testing conditions the aftertreatment valve is completely open and the by-pass valve closed. This procedure does not avoid the DPF thermal transient from one operating point to another but removes the influence of the DPF soot loading increase because of filtration during the thermal stabilisation phase.

According to this purpose, the valves were controlled following next steps, which are pictured in Figure 1:

1. The steady-state operating point to be tested is firstly stabilised bypassing the aftertreatment system (Picture A in Figure 1).

- Aftertreatment valve is fully closed.

- By-pass valve sets the engine back-pressure.

- Thermal stabilization ends when DPF outlet temperature does not vary. DPF outlet temperature is the temperature of tailpipe exhaust gas and is considered an indicator of engine thermal stabilization because it is the las temperature measured.

2. When the engine thermal transient ends, the aftertreament valve is completely opened and at the same time the regulation valve is closed (Picture B in Figure 1).

- The measurement is performed during $300 \mathrm{~s}$.

3. When the measurement is completed, the aftertreatment valve is closed at the same time than the regulation valve is opened. The engine is then driven to the next steady-state operating point (Picture $\mathrm{C}$ in Figure 1). 


\section{Results and discussion}

\subsection{Pollutants emission and particle behavior during the pre-DPF water injection event}

The main effects of the pre-DPF water injection technique on pollutant emissions take place during the transient period during which the injection event is performed. According to this transient response, the pattern of the particle and gaseous emissions during one injection event are analysed. For this purpose, the selected process corresponds to the first pre-DPF water injection event carried out during the DPF loading test. Figure 4 shows the entire DPF loading test pointing out the selected injection event for analysis. The soot loading test has a main interest to demonstrate that the reduction of the pressure drop brought by a single pre-DPF water injection in a soot loaded DPF can be applied to control the DPF pressure drop independently of the soot loading by chaining consecutive injection events. Further details on the test and the effects on the engine and DPF performance are described in [24].

\subsubsection{Gaseous emissions during a pre-DPF water injection event}

Figure 5 shows gaseous emissions profile during the first pre-DPF water injection event of the DPF soot loading test. Plot (A) in Figure 5 evidences a great increase of the water concentration in the exhaust gas at the DPF outlet just after the pre-DPF water injection is carried out. The increase in concentration is due to the fact that the water volume in the raw volumetric exhaust gas increases in comparison with the nominal operation. Nevertheless, it is interesting to note that the water injection lasts $3 \mathrm{~s}$ being the peak in water concentration shifted around $25 \mathrm{~s}$. The required time until the nominal level of water concentration is reached is around $250 \mathrm{~s}$. This time is related to the water vapour dwell time and coincides with the elapsed time until the DPF outlet temperature reaches its value before the injection event.

In this sense, when a pre-DPF water injection event is performed, despite of the high injection rate, most of the $\mathrm{H}_{2} \mathrm{O}$ is kept within the DPF and retained inside the porous wall. Initially, some part of water injected is evaporated due to the higher temperature of the exhaust gas and the porous substrate. The increase of specific humidity in the exhaust gas cools down it. The rest of water amount exceeds the evaporation rate in the porous surface so that the instantaneous evaporation of the total $\mathrm{H}_{2} \mathrm{O}$ amount is not possible. As time passes, the water is evaporated by the exhaust gas and as water is removed the temperature gradually increases again, because of the nominal specific humidity is recovery controlling the thermal transient related to the injection event.

The increase of water concentration in the exhaust gas flow causes a complementary dilution effect on the remainder exhaust gas compounds. For example, the injection of water in the gas stream leads the reduction in concentration in $\mathrm{CO}_{2}$ concentration (Figure 5.B). The required time to increase the $\mathrm{CO}_{2}$ concentration to the nominal value before the pre-DPF water injection event is equal to the $\mathrm{H}_{2} \mathrm{O}$ emission recuperation time. As expected, a similar trend to that shown by $\mathrm{CO}_{2}$ concentration is found in Figure 5.C for the NOx emission downstream of the DPF.

With respect to hydrocarbons and carbon monoxide emission, Figure 5.D and Figure 5.E represents both the light hydrocarbons $(<7 \mathrm{C})$ and $\mathrm{CO}$ concentration while the pre-DPF water injection event takes place. For these compounds, 
the nominal emissions are negligible being values affected by measurement noise. In this case, the pre-DPF water injection does not affect this trend being only observed some transient noise mitigation somehow due to the lower concentration because of greater water content.

Finally, Figure 5.F plots the profile of the $\mathrm{NO}$ and $\mathrm{NO}_{2}$ emission separately. Once the NOx emission is recovered after the $\mathrm{H}_{2} \mathrm{O}$ removal (250 s after water injection), an increase and decrease of $\mathrm{NO}$ and $\mathrm{NO}_{2}$ respectively was found with respect to their nominal values. Initially, a drop in both compounds is observed due to the described dilution effect caused by the water injection on the rest of compounds of the exhaust gas. After the first drop in concentration, Figure 5.F points out a change in $\mathrm{NO}$ and $\mathrm{NO}_{2}$ trend. This change is related to the gas temperature reduction which is also affecting the porous substrate of the DPF. The NO-to- $\mathrm{NO}_{2}$ equilibrium is strongly dependent on the temperature [34] so that the temperature decrease causes the increase and decrease in $\mathrm{NO}$ and $\mathrm{NO}_{2}$ concentration respectively as time passes. That is what happens until second 125 in Figure 5.F. When the exhaust gas temperature reaches again values over $230^{\circ} \mathrm{C}$, from second 125 inwards, the $\mathrm{NO}$ decrease slowly and complementary $\mathrm{NO}_{2}$ increases.

Although the instantaneous NO-to- $\mathrm{NO}_{2}$ equilibrium is modified when a pre-DPF water injection event is carried out, the overall emission is not affected. As example, Figure 6 shows $\mathrm{NO}$ and the $\mathrm{NO}_{2}$ emissions during the soot loading test shown in Figure 4. In Figure 6 the emissions of NOx from the baseline DPF operation hace been compared with the consecutive pre-DPF water injection emissions. Although at the beginning of the test small differences in total $\mathrm{NO}_{\mathrm{x}}$ concentration can be observed between both tests, the $\mathrm{NO}_{2}$ and $\mathrm{NO}$ trend is the same being the influence of the pre-DPF water injection technique completely negligible, even considering that passive regeneration is taking place. At the beginning of both tests, the thermal transient of the engine controls the $\mathrm{NO}_{2}$ emission increase and the complementary $\mathrm{NO}$ decrease. The NO-to- $\mathrm{NO}_{2}$ ratio finally stabilises keeping constant about a soot loading of $3 \mathrm{~g}$. From $3 \mathrm{~g}$ soot loading, the $\mathrm{NO}_{2}$ emission begins to decrease slightly while $\mathrm{NO}$ increases. As the engine operates under steady-state conditions, this change in the NO-to- $\mathrm{NO}_{2}$ ratio evidences the beginning of the soot oxidation due to passive regeneration phenomena.

\subsubsection{Particle emission during a pre-DPF water injection event}

Figure 7 shows the opacity measurement downstream of the DPF during a pre-DPF water injection event. Additionally, the filter smoke number (FSN) was measured before, during and after the pre-DPF water injection event being the results also plotted in Figure 7.

When the pre-DPF water injection starts, the measurement points out an almost instantaneous increase of the emitted opacity. The sharp opacity increase is related to the effect of the water injection and a small drag effect on the particulate collected on and inside the porous substrate [24]. The results from Figure 7 fully correlate with water concentration increment showed in Figure 5.A. Nevertheless, the maximum peak in opacity is kept at a very low magnitude what points out that the pressure drop decrease is not related to soot mass release.

Two peaks are clearly identified during that sudden opacity increase. The first peak is due to the pressure perturbation at the DPF inlet caused by the water injection, since the water injection pressure is 0.5 bar above the gas pressure 
at the DPF inlet [24]. The second peak is related the water residence inside the DPF monolith. The cause lies in the drag induced by the water stream on the soot particles. It produces the pressure drop reduction (p in Figure 7) because of the restructuring of the particulate layer and the soot collected inside the porous wall but a small quantity of soot can be released because of this process. Furthermore, the increase in soot emission duration and the peak location, which is close to second 25 after pre-DPF water injection event, coincides with the main phase of water removal from the monolith, as shown in Figure 5.A.

The instantaneous opacity measurement is corroborated by the FSN measurements performed downstream of the DPF. Before the beginning of the pre-DPF water injection the FSN value was 0.02. During the pre-DPF water injection the FSN was also measured in order to check the opacity trend. The measurement provided a 0.55 FSN value. Filters colour comparison is shown in Figure 7. It is important to note that the opacimeter provides a continuous measurement for transient operation but AVL®415S providing the FSN value only performs steady-state measurements. Therefore the FSN measurements were carried out during ten seconds.

The analysis of soot emission during a pre-DPF water injection event is completed with the analysis of the particle number emission as a function of the particle size. Figure 8.A shows a detail of the particle emission during preDPF water injection based on particle concentration. The trend fully agrees with that obtained by the opacimeter and shown in Figure 7. The maximum in particle concentration downstream of the DPF is two orders of magnitude higher than the nominal value before the pre-DPF water injection $\left(4.6 \cdot 10^{13} \# / \mathrm{m}^{3}\right.$ vs. $\left.6.1 \cdot 10^{11} \# / \mathrm{m}^{3}\right)$. As concluded from the opacity values, this increase is negligible in terms of soot mass emitted. During the transient particle emission increase the estimated soot mass release is lower than $2 \mathrm{mg}$, which is not significant in comparison to the DPF soot mass loading (varying from $10 \mathrm{~g}$ to $30 \mathrm{~g}$ for this experiment).

In order to describe in detail this behavior, Figure 8.B compares the PSD downstream of the DPF in three different instants, i.e: before, during and after the pre-DPF water injection event. The comparison between the PSD before (20 s) and after (300 s) pre-DPF water injection reveals a similar distribution of particle emission as a function of the particle diameter. It can be seen that in both cases the mode of the PSD emitted in the tailpipe is $52.3 \mathrm{~nm}$. Comparing these emission with that taking place during the water injection event (80 s), and as concluded from Figure 8.A, there is an increase in particle number emission that covers the range $30 \mathrm{~nm}$ and $200 \mathrm{~nm}$. Although in mass is not significant, the most interesting fact is that a change in the mode of the PSD is appearing. It moves from $52.3 \mathrm{~nm}$ to $69.8 \mathrm{~nm}$, diameter that coincides with the mode of raw PSD upstream the DPF, as shown in Figure 8.C.

Additionally, Figure 9 shows the tailpipe particle concentration during the pre-DPF water injection event but discretised as a function of the particle diameter. This plot confirms that the change in the mode of the particle diameter emitted shown in Figure 8.B takes place during the whole process. This result strengthens the hypothesis about the water drag on soot deposits but also that these are characterised by the mode of the soot aggregates, which are controlling the pressure drop and filtration phenomena and must be present in modelling approaches [18]. 


\subsection{Total particle emission and particle size distribution during the DPF loading process}

In parallel to the analysis of the pressure drop during the soot loading process [24], the particle emissions both upstream and downstream of the DPF were also measured. Downstream particle measurements have been done in continuous mode, while upstream measurements were carried out every hour changing the valve position to DPF inlet (DPF inlet valve in Figure 1) during $120 \mathrm{~s}$. This procedure provides the characterisation of the particle emission both upstream and downstream of the DPF. Therefore it is possible to evaluate both the overall DPF filtration efficiency and as a function of the particle size diameter providing the basis for a complete DPF response analysis.

Figure 10 depicts the comparison on raw and tailpipe particle number concentration and the PSD during the DPF loading process between the tests with baseline configuration and the use of consecutive pre-DPF water injection events. Plots (A) and (B) in Figure 10 show the PSD both upstream and downstream of the DPF. The series correspond to different hours during the soot loading test being the continuous lines corresponding to the raw PSD at the DPF inlet and the dashed lines to the tailpipe PSD.

As Figure 10.A shows, during the baseline DPF loading test an increase in the particle number concentration of raw and tailpipe particle emission is observed, affecting all the particle diameters. The increase in raw PSD is produced by the exhaust back-pressure increase [35] due to the DPF soot loading.

These trends are corroborated in Figure 10.C, which provides as a summary the total particle concentration. On one hand, DPF inlet total particle concentration at the end of the DPF loading test increases around $17 \%\left(3.5 \cdot 10^{16} \# / \mathrm{m}^{3}\right)$ with respect to the first measurement performed (one hour after the test beginning). On the other hand, the total particle concentration downstream of the DPF suffers a percentage increase of $44 \%\left(2.49 \cdot 10^{10} \# / \mathrm{m}^{3}\right)$ at the end of the loading phase and with respect to the first measurement performed.

The analysis of the particle emission during the DPF loading test with application of the pre-DPF water injection technique reveals several variations with respect to the baseline configuration. One of the changes observed concerns the PSD upstream of the DPF (Figure 10.B), since it is kept almost constant throughout the test. The use of consecutive applications of the pre-DPF water injection technique brings control to the DPF pressure drop, which can be kept constant with independence of the soot loading, as shown in Figure 4. Consequently, the lack of change in the exhaust back-pressure leads to constant raw soot emission both in total particle concentration and PSD provided that the EGR rate remain constant according to the ECU control. Figure 10.D shows a flat line in raw total particle concentration along the entire DPF loading test, allowing accurate control on particle emission.

The other important change in particle emissions regards the decrease in number concentration as a function of the particle size taking place in the last phase of the loading test, as shown in Figure 10.B. Consequently the total particle concentration is also decreasing as a time function, what is represented in Figure 10.D. According to the trend in raw and tailpipe particle emission during the test, the changes in the structure of the soot deposits is producing an increase of the DPF filtration efficiency. 


\subsubsection{DPF filtration efficiency during a DPF loading test}

The DPF filtration efficiency based on particle number concentration is calculated as a function of particle size according to:

$$
F E_{\text {number }}\left(D n_{i}\right)=100\left[1-\frac{n_{\text {down }}\left(D n_{i}\right)}{n_{u p}\left(D n_{i}\right)}\right]
$$

In eq (1), $n_{u p}$ and $n_{\text {down }}$ are the values of particle number concentration at diameter $D n_{i}$ upstream and downstream of the DPF respectively.

Figure 11 shows a comparison between the DPF filtration efficiency evolution during both DPF loading tests. On one hand, the DPF filtration efficiency decreases slightly as a time function during the baseline DPF loading test. Figure 11.A shows that the overall filtration efficiency is only slightly affected and is kept inside the range $99.75 \%$ to 99.5\% during the whole test. The same order of magnitude in overall filtration efficiency has been found in the case of the soot loading test applying the pre-DPF water injection technique. Nevertheless, and as inferred from results shown in Section 4.2, the filtration efficiency shows an increase rate during the test. The explanation for this behaviour must be found in the changes of the soot deposits structure because of the soot distribution inside the porous wall. It is known that in baseline DPF operation, the penetration of the soot particles inside the porous walls is usually very small. Only a reduced fraction of the porous wall is saturated with soot particles as shown in different experimental works [36] and theoretical studies based on 1D models [18] or Lattice-Boltzmann approaches [37].

Therefore, the water drag across the porous wall, which justifies the slight increase in soot emission, is supposed to be also producing an increase of the soot mass inside the porous wall and also greater penetration. On one hand, this process provides lower pressure drop because of the more homogeneous distribution of soot inside the porous wall and the lower effective permeability of the porous wall [18] and adds to contribution of the particulate layer restructuring [18]. On the other hand, the better use of the whole porous wall thickness provides greater filtration efficiency of the system [17].

With respect to the detail in filtration efficiency as a function of the particle diameter, Figure 11.C and Figure 11.D. which are referred to baseline and pre-DPF water injection tests respectively, show the same trend. Three local minimum values in filtration efficiency located at the same particle size. The first local minimum is located in $10 \mathrm{~nm}$ and is related with the loss of filtration efficiency for ultra-fine particles [38]. The second local minimum is found around $22 \mathrm{~nm}$. This diameter is characteristic for this DPF and is related with the DPF geometrical properties and the volumetric flow through the DPF [39]. Finally, the minimum filtration efficiency is located around the region of $200 \mathrm{~nm}$, where is defined the most penetrating diameter because of low filtration efficiency of all contributing mechanisms, i.e. brownian diffusion, interception and inertial impaction. 


\subsection{Effects on PSD under steady-state operating conditions}

After every DPF loading test, three steady-state operating points at low load (Table 4) were tested in order to assess its DPF filtration efficiency under baseline DPF operation and having been applied the pre-DPF water injection technique. These steady-state operating points were tested applying the methodology described in Section 3.1.

On one hand, Figure 12.A shows the particle size distribution at DPF inlet corresponding to the low load steadystate points \#A, \#B and \#C defined in Table 4. The comparison between baseline tests and pre-DPF water injection use reveals that as expected the engine raw emission is very similar. In the same way, Figure 12.B depicts the particle size distribution downstream of the DPF. It is clearly shown that the use of the pre-DPF water injection technique is not affecting the tailpipe PSD, so that it can be advanced the same trend in filtration efficiency.

This is shown in Figure 12.C. The deviations between the baseline tests and the tests performed after applying preDPF water injections are negligible. It can be seen how the filtration efficiency profile is the same as a function of the particle size, including the minimum local efficiency in the fine particles region and concerning the most penetrating particle size. Slightly lower efficiency has been measured at local minimum of $200 \mathrm{~nm}$ after aplication of water injection at point \#B and slightly higher efficiency has been also measured at local minimum of $22 \mathrm{~nm}$ after water injection in point \#A. Nevertheless, the similarities in filtration efficiency are evident when these values are integrated to assess the overall filtration efficiency, which is shown in Table 6. Significant differences have not been found due to use of pre-DPF water injection. Therefore, it is possible to conclude that there are not negative influence of the pre-DPF water injection technique on the soot collection capability of state of the art wall-flow DPFs.

\subsection{Passive regeneration under high load steady-state operating conditions.}

The last study assessed in this work concerns the analysis of the loaded DPF response under high load steady-state operating conditions when passive regeneration is taking place. The methodology applied to perform these tests is described in Section 3.1. The objective is to complete the DPF regeneration passively testing operating points \#D, \#E and \#F (Table 5) consecutively but by-passing the aftertreatment in the engine stabilisation period between the transition from one point to another.

The test began with the operating point \#D. Figure 13.A1 shows how the DPF pressure drop is lower in the case of pre-DPF water injection previously applied to the DPF. The pressure drops remain constant during the whole test what points out that the DPF is not being suffering passive regeneration. Although the gas temperature, which is shown in Figure 13.A2, is over $400^{\circ}$ the flow dwell time in this operating point is reduced. Figure 14.A and Figure 14.B shows the particle size distribution upstream and downstream of the DPF. The analysis of the results for point \#D also indicates that the DPF behaves similarly in both tests (baseline \& pre-DPF water injection) since for the same raw PSD the tailpipe emission coincides.

After the test of the operating point \#D, the aftertreatment valve is closed and the by-pass valve opened (Picture A of by-pass valve system showed in Figure 1) to control the exhaust back-pressure during the stabilisation of the point \#E. When the flow is again driven across the DPF a change in the DPF pressure drop trend is found between 
the baseline test and the use of the pre-DPF water injection technique. In fact, the DPF pressure drop is now lower in the baseline test. The cause lies in the DPF behaviour whilst it was by-passed. As the flow is removed from the DPF, stopping the gas at high temperature, it is similar to a drop-to-idle test. Consequently, the DPF undergoes a passive regeneration process. Figure 13.B2 confirms that this is happening in both tests since the outlet DPF gas temperature is higher than the inlet one just at the beginning of the test. Nevertheless, the change in pressure drop trend evidences that the rate of regeneration has been higher in the case of the baseline test whose pressure drop is now slightly lower than that corresponding to the test with use of pre-DPF water injection. Regarding point \#E, Figure 14.A shows similar PSD upstream of the DPF. However, Figure 14.B indicates that the tailpipe particle emission at the end of the operating point testing in the baseline case is clearly higher independently the particle size. The reason for a slightly particle emission is due to the particle reestructuration inside the porous wall when pre-DPF water injection events are carried out during the DPF loading phase, as proposed by Serrano et al. [24].

Finally, similar trend than \#E steady-state operating point is showed by \#F, as shown Figure 13.C1. For this operating point, at the beginning of the aftertreatment valve opening, the pressure drop is lower in the baseline case, what again points out higher passive regeneration in the DPF during the phase without flow across the DPF. It is also confirmed by sudden increase of outlet DPF gas temperature for the baseline test (Figure 13.C2). At the end of the test, once in both cases have been reached the same pressure drop, Figure 14.B shows that for point \#F the tailpipe PSD is higher in the case of the baseline DPF case.

Therefore, it can be concluded that in general terms the passive regeneration is not affected when pre-DPF water injection technique is applied. Nevertheless, at high soot loading the rate of regeneration has been slightly higher in the case of the baseline configuration although reaching the DPF pressure drop value corresponding to the clean conditions at the same time.

\section{Summary and conclusions}

The objective of this work has been to investigate the particle and gaseous pollutant emission related to the use of pre-DPF water injection as a technique to limit and control the pressure drop in loaded DPFs. The analysis is based on the comparison against DPF baseline operation during a DPF soot loading test and steady-state operating conditions at low and high engine load.

The study firstly focuses on the analysis of gaseous and particle emission during a pre-DPF water injection event. Secondly it is discussed the global DPF performance in terms of filtration efficiency when pre-DPF water injection is applied during engine operation and in comparison to baseline DPF management. For this purpose the raw and tailpipe soot emission is assessed during a DPF soot loading in which consecutive water injection events are performed to keep constant the DPF pressure drop, and also atsteady-state conditions. A broad engine operating range, even passive regeneration conditions have been covered. The main findings of the performed work are summarised as follows.

During every pre-DPF water injection event, it has been observed that: 
- The water injection into the exhaust gas causes an overall dilution effect in other pollutants because of the increase of exhaust mass flow. As the water concentration comes back to the nominal value the nominal concentration of the remainder compounds is also recovered, without any influence of the proposed technique.

- A negligible release of soot mass has been detected during a pre-DPF water injection event. It has been confirmed by measuring opacity, FSN and particle concentration at the exhaust tailpipe.

- The mode in PSD at the DPF outlet is modified during the pre-DPF water injection event. During this phase, this mode coincides with the mode of the raw particle emission at the DPF inlet.

Considering the global DPF response when pre-DPF water injections are applied during its operation, i.e. the influence on the overall behaviour, it can be concluded that:

- A control of raw PSD during DPF loading test is possible due to the fact that it is possible to decouple the engine operation from the DPF soot loading.

- The filtration efficiency during the DPF loading test is not affected both concerning overall value and as a function of the particle size.

- The filtration efficiency is also kept under steady-state operating conditions tested after pre-DPF water injection application.

- The rate of passive regeneration during DPF loading test shows the same trend and dynamics in both cases, being unaffected by the application of pre-DPF water injection technique.

- Similarly, the passive regeneration performance is kept at low load steady-state conditions with lower particle emission in the case of previous application of the pre-DPF water injection technique.

\section{Acknowledgements}

This work has been partially supported by FEDER project funds "Dotación de infraestructuras científico técnicas para el Centro Integral de Mejora Energética y Medioambiental de Sistemas de Transporte (CiMeT), (FEDER- ICTS2012-06)", framed in the operational program of unique scientific and technical infrastructure of the Ministry of Science and Innovation of Spain.

\section{References}

\section{References}

[1] Zervas E, Poulopoulos S, Philippopoulos C. $\mathrm{CO}_{2}$ emissions change from the introduction of diesel passenger cars: case of greece, Energy 2006;31(14):2915-25. 
[2] Oberdorster G, Utell MJ. Ultrafine particles in the urban air: to the respiratory tract and beyond, Environ Health Persp 2002;110(8):A440-41.

[3] Pope C, Dockery D. Health effects of fine particulate air pollution: lines that connect, J Air Waste Manage 2006;56(6):709-42.

[4] Kennedy IM. The health effects of combustion-generated aerosols, P Combust Inst 2007;31(2):2757-70.

[5] Desantes JM, Luján JM, Pla B, Soler JA. On the combination of high-pressure and low-pressure exhaust gas recirculation loops for improved fuel economy and reduced emissions in high-speed direct-injection engines, Int J Engine Res 2013;14(1):3-11

[6] Macian V, Payri R, Ruiz S, Bardi M, Plazas AH. Experimental study of the relationship between injection rate shape and diesel ignition using a novel piezo-actuated direct-acting injector, Appl Energ 2014;118:100-13.

[7] Benajes J, Novella R, De Lima D, Tribott P, Quechonb N, Obernesser P, Dugue V. Analysis of the combustion process, pollutant emissions and efficiency of an innovative 2-stroke HSDI engine designed for automotive applications, Appl Therm Eng 2013;58:181-93.

[8] Molina S, Guardiola C, Martín J, García-Sarmiento D. Development of a control-oriented model to optimise fuel consumption and NOx emissions in a DI Diesel engine, Appl Energ 2014;119:405-16

[9] Galindo J, Luján JM, Serrano JR, Dolz V. Design of an exhaust manifold to improve transient performance of a high-speed turbocharged diesel engine, Appl Therm Eng 2008;28(8):863-75.

[10] Dardiotis C, Martini G, Marotta A, Manfredi U. Low-temperature cold-start gaseous emissions of late technology passenger cars, Appl Energ 2013;111:468-78.

[11] 2008/692/EC, Implementing and amending regulation (EC) n. 715/2007 of the European parliament and of the council on type-approval of motor vehicles with respect to emissions from light passenger and commercial vehicles (EURO 5 and EURO 6) and on access to vehicle repair and maintenance information.

[12] Konstandopoulos AG, Margaritis K, Skaperdas E, Papaioannou E, Zarvalis D, Kladopoulou E. Fundamental studies of diesel particulate filters: Transient loading, regeneration, and aging, in: SAE Technical Paper 2000-01-1016, 2002.

[13] Yamamoto K, Oohori S, Yamashita S, Daido S. Simulation on soot deposition and combustion in diesel particulate filter, P Combust Inst 2009;32(2):1965-72.

[14] Li J, Mital R. Effect of DPF design parameters on fuel economy and thermal durability, in: SAE Technical Paper 2012-01-0847, 2012.

[15] Torregrosa AJ, Serrano JR, Arnau FJ, Piqueras P. A fluid dynamic model for unsteady compressible flow in wall-flow diesel particulate filters, Energy 2011;36(1):671-84.

[16] Payri F, Broatch A, Serrano JR, Piqueras P. Experimental-theoretical methodology for determination of inertial pressure drop distribution and pore structure properties in wall-flow diesel particulate filters (DPFs), Energy 2011;36(12):6731-44.

[17] Tandon P, Heibel A, Whitmore J, Kekre N, Chithapragada K. Measurement and prediction of filtration efficiency evolution of soot loaded diesel particulate filters, Chem Eng Sci 2010;65(16):4751-60.

[18] Serrano JR, Arnau FJ, Piqueras P. Garcia-Afonso O, Packed bed of spherical particles approach for pressure drop prediction in wall-flow DPFs under soot loading conditions, Energy 2013;58:644-54.

[19] Tsuneyoshi K, Yamamoto K. A study on the cell structure and the performances of wall-flow diesel particulate filter, Energy 2012;48(1):49299.

[20] Beatrice C, Di Iorio S, Guido C, Napolitano P. Detailed characterization of particulate emissions of an automotive catalyzed dpf using actual regeneration strategies, Exp Therm Fluid Sci 2012;39:45-53.

[21] Bermúdez V, Serrano JR, Piqueras P, García-Afonso Ó. Assessment by means of gas dynamic modelling of a pre-turbo diesel particulate filter configuration in a turbocharged HSDI diesel engine under full-load transient operation, P I Mech Eng D-J Aut 2011;225(9):1134-55.

[22] Bermúdez V, Serrano JR, Piqueras P, García-Afonso Ó. Analysis of heavy-duty turbocharged diesel engine response under cold transient operation with a pre-turbo aftertreatment exhaust manifold configuration, Int J Engine Res 2013;14(4):341-53.

[23] Bermúdez V, Luján JM, Piqueras P, Campos D. Pollutants emission and particle behavior in a pre-turbo aftertreatment light-duty diesel engine, Energy 2014;66:509-22.

[24] Serrano JR, Bermúdez V, Piqueras P, Garcia-Afonso O. Pre-DPF water injection technique for pressure drop control in loaded wall-flow diesel particulate filters, Submitted to Appl Energ. 


\section{Nomenclature}

Abbreviations

BTDC

before top dead center

$\mathrm{CO}$ carbon monoxide

$\mathrm{CO}_{2} \quad$ carbon dioxide

DOC diesel oxidation catalyst

465

DPF

ECU

ED

EEPS

EGR

FE

FPS

FSN diesel particulate filter

electronic control unit

ejector diluter

engine exhaust particle sizer

exhaust gas recirculation

filtration efficiency

fine particle sampler

filter smoke number 


$\begin{array}{ll}\text { F-TIR } & \text { fourier transform infrared spectroscopy } \\ \text { HC } & \text { unburned hydrocarbons } \\ \text { HSDI } & \text { high-speed direct injection } \\ \mathrm{n} & \text { particle number concentration } \\ \text { NEDC } & \text { new European driving cycle } \\ \text { NO } & \text { nitrogen monoxide } \\ \text { NO } 2 & \text { nitrogen dioxide } \\ \text { NOx } & \text { nitrogen oxides } \\ \text { PM } & \text { particulate matter } \\ \text { pre-DOC } & \text { close-coupled diesel oxidation catalyst } \\ \text { PSD } & \text { particle size distribution } \\ \text { PTD } & \text { porous tube dilution } \\ \text { SOI } & \text { start of injection } \\ \text { SR-EGR } & \text { Short route exhaust gas recirculation } \\ \text { ULSD } & \text { ultra low sulfur diesel }\end{array}$

\section{List of Tables}

- Table 1.- Engine main characteristics.

- Table 2.- Aftertreatment characteristics.

- Table 3.- Fuel properties.

- Table 4.- Low load steady-state operating points for filtration efficiency analysis. Main parameters.

- Table 5.- High load steady-state operating points for passive regeneration analysis. Main parameters.

- Table 6.- Comparison in overall DPF filtration efficiency under low load steady-state operating conditions between the baseline configuration and the use of the pre-DPF water injection technique.

\section{List of Figures}

- Figure 1.- Experimental setup for measurement of pollutant emissions with use of pre-DPF water injection technique and sequence of the by-pass system control placed.

- Figure 2.- Methodology to condition the exhaust gas sample for particle size distribution measurement [30].

- Figure 3.- "Test-set" performed with baseline configuration and the use of pre-DPF water injection technique.

- Figure 4.- DPF pressure drop evolution during DPF soot loading including pre-DPF water injections. Selected pre-DPF water injection for analysis.

- Figure 5.- Gaseous emissions evolution during a pre-DPF water injection event.

- Figure 6.- Comparison of the $\mathrm{NO}$ and $\mathrm{NO}_{2}$ tailpipe emission during the DPF loading test between baseline DPF and the application of pre-DPF wter injection. 
- Figure 7.- Opacity profile and FSN values during a pre-DPF water injection event.

- Figure 8.- Particle number concentration evolution during a pre-DPF water injection event. A) Total particle number concentration evolution. B) Tailpipe particle size distribution evaluated before, during and after the pre-DPF water injection event. C) Raw particle size distribution at the inlet of the DPF compared to tailpipe particle size distribution during pre-DPF water injection event (Peak).

- Figure 9.- Evolution of the tailpipe particle number concentration as a function of the particle diameter during a pre-DPF water injection event.

- Figure 10.- Particle size distribution and total particle concentration during DPF loading test. A) Raw and tailpipe PSD during the baseline DPF loading test. B) Raw and tailpipe PSD during the DPF loading test with use pre-DPF water injection technique. C) Raw and tailpipe total particle concentration during the baseline DPF loading test. D) Raw and tailpipe total particle concentration during the DPF loading test with use pre-DPF water injection technique.

- Figure 11.-DPF filtration efficiency during DPF loading test. A) Overall DPF filtration efficiency during the baseline DPF loading test. B) Overall DPF filtration efficiency during the DPF loading test with use pre-DPF water injection technique. C) DPF filtration efficiency as a function of the particle size during the baseline DPF loading test. D) DPF filtration efficiency as a function of the particle size during the DPF loading test with use pre-DPF water injection technique.

- Figure 12.- Comparison in raw and tailpipe particle number concentration and DPF filtration efficiency as a function of the particle size during the test of the steady-state operating conditions at low load.

- Figure 13.- DPF pressure drop and gas temperature during the test of the steady-state operating conditions at high load comparing between baseline test and use of the pre-DPF water injection technique.

- Figure 14.- Raw and tailpipe particle size distribution during the test of the steady-state operating conditions at high load comparing between baseline test and use of the pre-DPF water injection technique. 
Table 1: Engine main characteristics.

\begin{tabular}{lcc}
\hline \hline Type & {$[-]$} & HSDI \\
Emission standards & {$[-]$} & EURO 4 \\
Displacement & {$\left[\mathrm{cm}^{3}\right]$} & 1997 \\
Bore & {$[\mathrm{mm}]$} & 85 \\
Stroke & {$[\mathrm{mm}]$} & 88 \\
Number of cylinders & {$[-]$} & 4 in line \\
Number of valves & {$[-]$} & 4 per cylinder \\
Compression ratio & {$[-]$} & $18: 1$ \\
Maximum power @ speed & {$[\mathrm{kW}]$} & $100 @ 4000 \mathrm{rpm}$ \\
Maximum torque @ speed & {$[\mathrm{Nm}]$} & $320 @ 1750 \mathrm{rpm}$ \\
\hline \hline
\end{tabular}

Table 2: DPF characteristics.

\begin{tabular}{lcc}
\multicolumn{3}{c}{ Table 2: DPF characteristics. } \\
\hline \hline Diameter & {$[\mathrm{mm}]$} & 132 \\
Length & {$[\mathrm{mm}]$} & 200 \\
Volume & {$[1]$} & 2.73 \\
Cell density & {$[\mathrm{cpsi}]$} & 200 \\
Honeycomb cell size & {$[\mathrm{mm}]$} & 1.486 \\
Wall thickness & {$[\mathrm{mm}]$} & 0.31 \\
No of channels & {$[-]$} & 4246 \\
Filtration area & {$\left[\mathrm{m}^{2}\right]$} & 2.5 \\
Specific permeability & {$\left[\mathrm{m}^{2}\right]$} & $2.49 \times 10^{-13}$ \\
\hline \hline
\end{tabular}

Table 3: Fuel properties.

\begin{tabular}{lcc}
\hline \hline Cetane number & {$[-]$} & 51.6 \\
Viscosity at $40^{\circ} \mathrm{C}$ & {$\left[\mathrm{mm}^{2} / \mathrm{s}\right]$} & 2.46 \\
Density at $15^{\circ} \mathrm{C}$ & {$[\mathrm{kg} / \mathrm{l}]$} & 0.843 \\
Lower heating value & {$[\mathrm{MJ} / \mathrm{kg}]$} & 42.055 \\
Sulfur content & {$[\mathrm{ppm}]$} & 6.6 \\
Water content & {$[\mathrm{ppm}]$} & 96 \\
\hline \hline
\end{tabular}


Table 4: Low load steady-state operating points for filtration efficiency analysis. Main parameters.

\begin{tabular}{cccccc}
\hline \hline Point & Speed & Torque & Load & SOI & EGR \\
\hline \hline \#A & 1580 & 45 & 15.7 & -2.98 & 36.5 \\
\#B & 1660 & 103 & 34.1 & -3.54 & 14 \\
\#C & 2240 & 94 & 32. & -1.2 & 13 \\
\hline \hline
\end{tabular}

Table 5: High load steady-state operating points for passive regeneration analysis. Main parameters.

\begin{tabular}{cccccc}
\hline \hline Point & Speed & Torque & Load & SOI & EGR \\
\hline & {$[\mathrm{rpm}]$} & {$[\mathrm{Nm}]$} & {$[\%]$} & {$\left[{ }^{\circ}\right.$ BTDC] } & {$[\%]$} \\
\hline \hline \#D & 4000 & 118 & 50 & -1.3 & 0 \\
\#E & 3500 & 173 & 70 & -15.9 & 0 \\
\#F & 2000 & 245 & 80 & -15.5 & 0 \\
\hline \hline
\end{tabular}

Table 6: Comparison in overall DPF filtration efficiency under low load steady-state operating conditions between the baseline configuration and the use of the pre-DPF water injection technique.

\begin{tabular}{ccc}
\hline \hline Point & Baseline & Pre-DPF water injection \\
\hline & {$[\%]$} & {$[\%]$} \\
\hline \hline \#A & 99.70 & 99.71 \\
$\#$ \# & 99.75 & 99.78 \\
$\#$ \# & 99.82 & 99.81 \\
\hline \hline
\end{tabular}




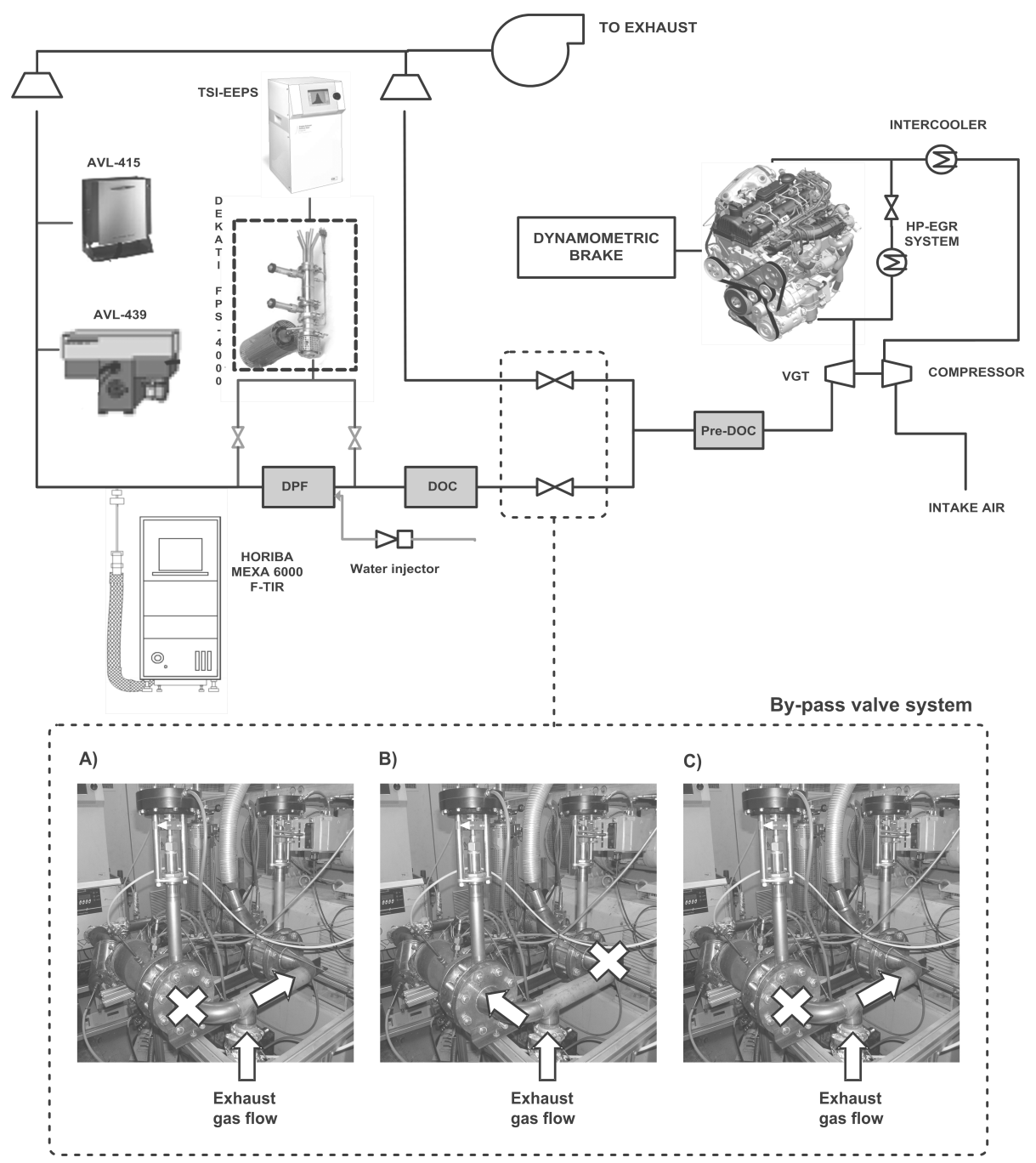

Figure 1: Experimental setup for measurement of pollutant emissions with use of pre-DPF water injection technique and sequence of the by-pass system control placed. 


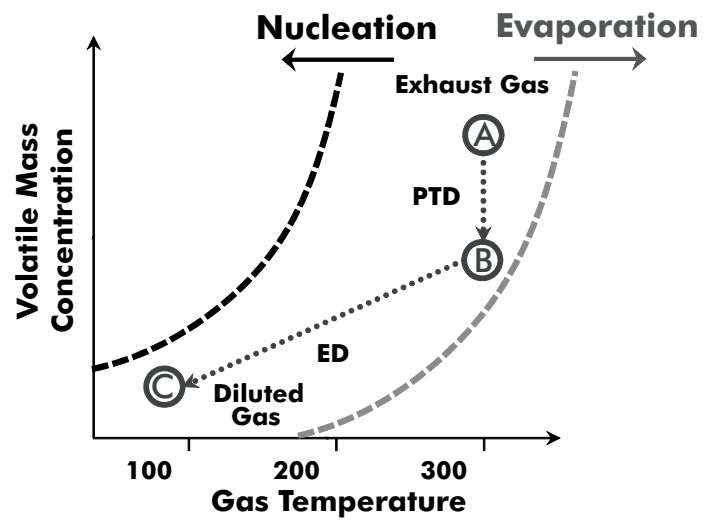

Figure 2: Methodology to condition the exhaust gas sample for particle size distribution measurement [30].

\section{“Test set" without pre-DPF water injections (Baseline)}

\begin{tabular}{|l|}
\hline $\begin{array}{l}\text { DPF loading test } \\
\text { without pre-DPF } \\
\text { water injections }\end{array}$ \\
wartial load \\
operating point
\end{tabular} \mid \begin{tabular}{c|c|}
$\begin{array}{c}\text { High load } \\
\text { steady-state } \\
\text { steady-state } \\
\text { operating point }\end{array}$ \\
\hline
\end{tabular}

\section{"Test set" applying pre-DPF water injection technique}

\begin{tabular}{|c|}
\hline $\begin{array}{c}\text { DPF loading test } \\
\text { with pre-DPF } \\
\text { water injections }\end{array}$ \\
wartial load \\
$\begin{array}{c}\text { Pady-state } \\
\text { steadyerating point }\end{array}$
\end{tabular}

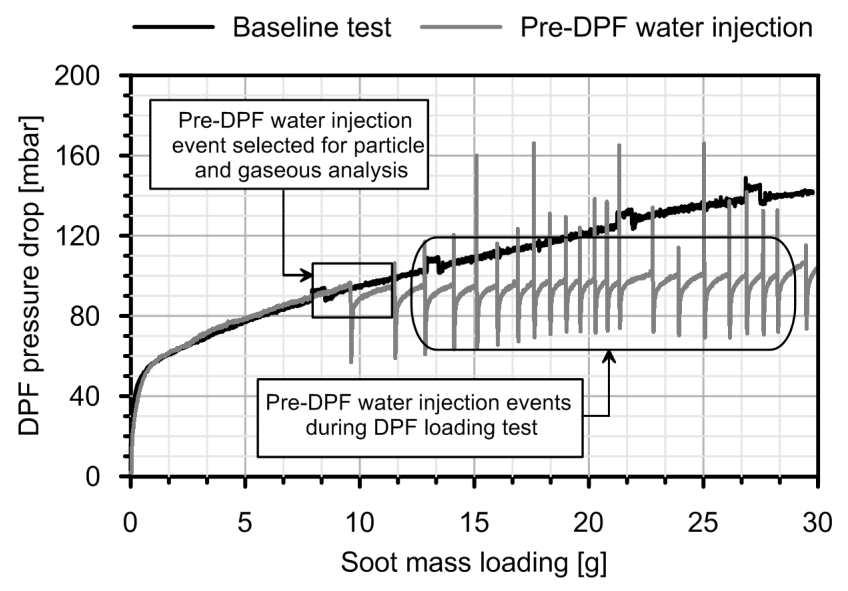

Figure 4: Application of the pre-DPF water injection technique for control of the DPF pressure drop during soot loading processes. 
A)

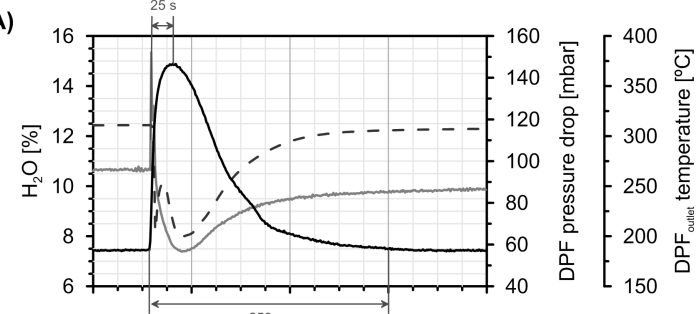

B)

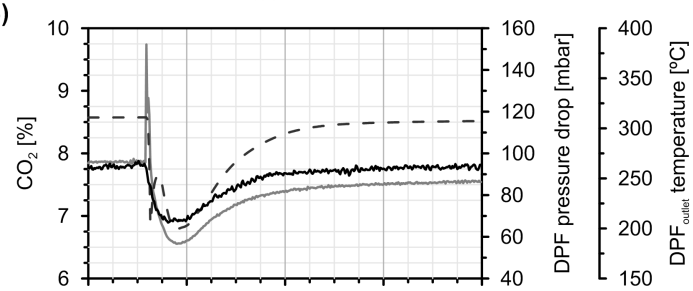

C)

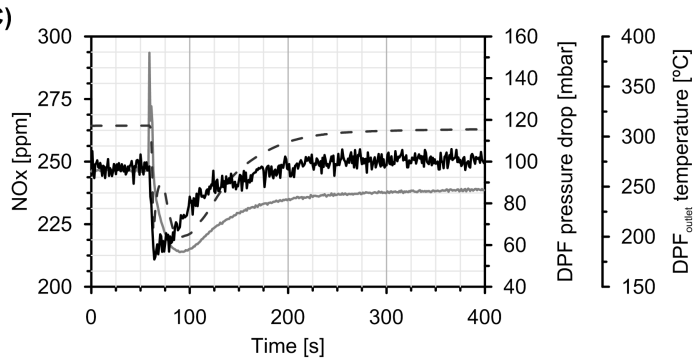

D)

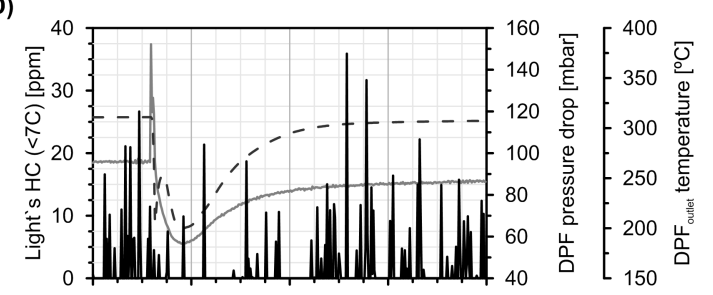

E)

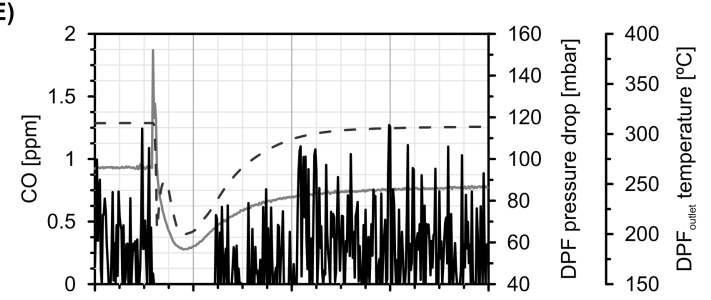

F)

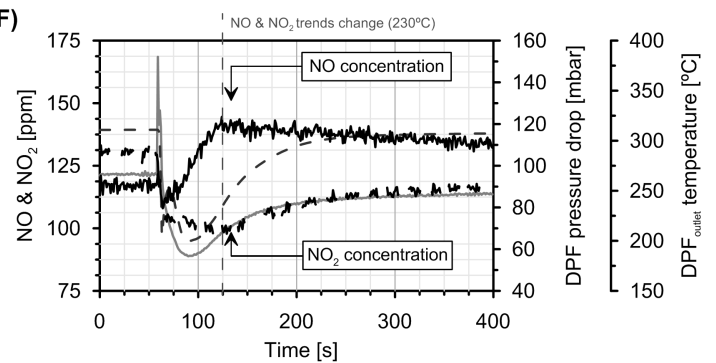

Figure 5: Gaseous emissions evolution during a pre-DPF water injection event.

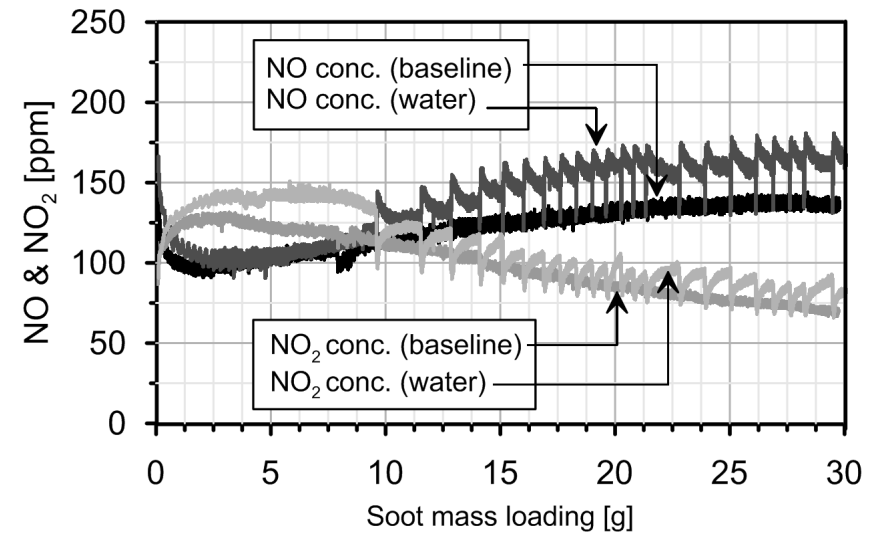

Figure 6: Comparison of the NO and $\mathrm{NO}_{2}$ tailpipe emission during the DPF loading test between baseline DPF and the application of pre-DPF wter injection. 


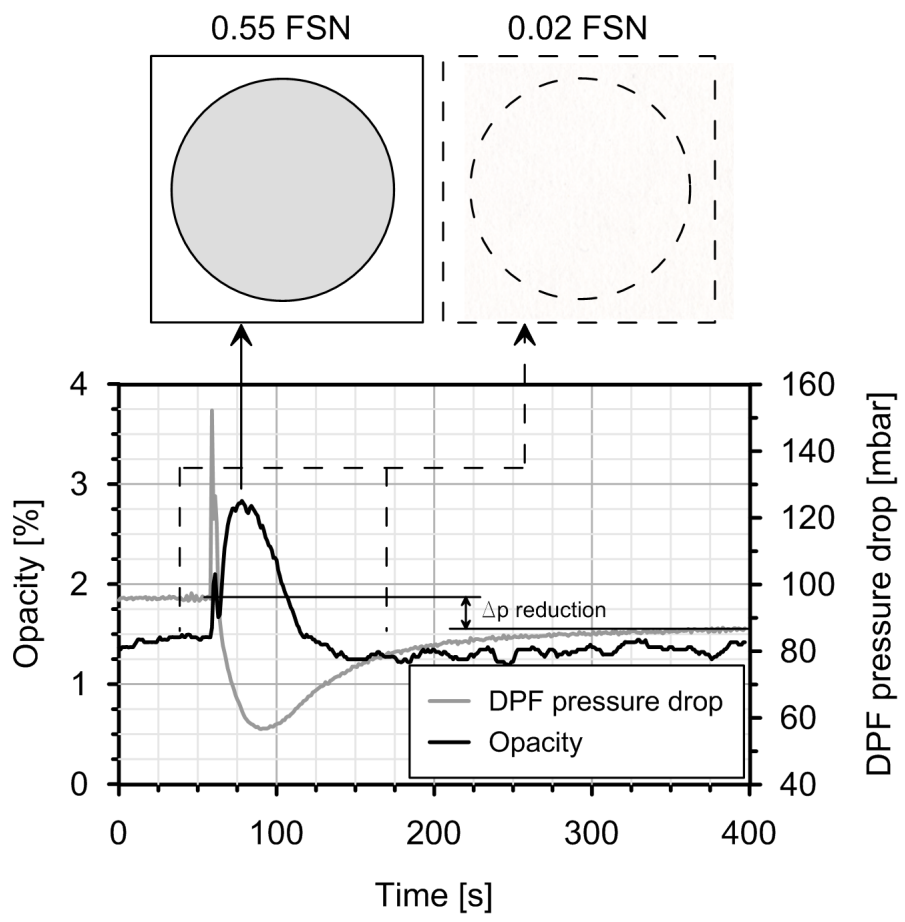

Figure 7: Opacity profile and FSN values during a pre-DPF water injection event. 


\section{A)}
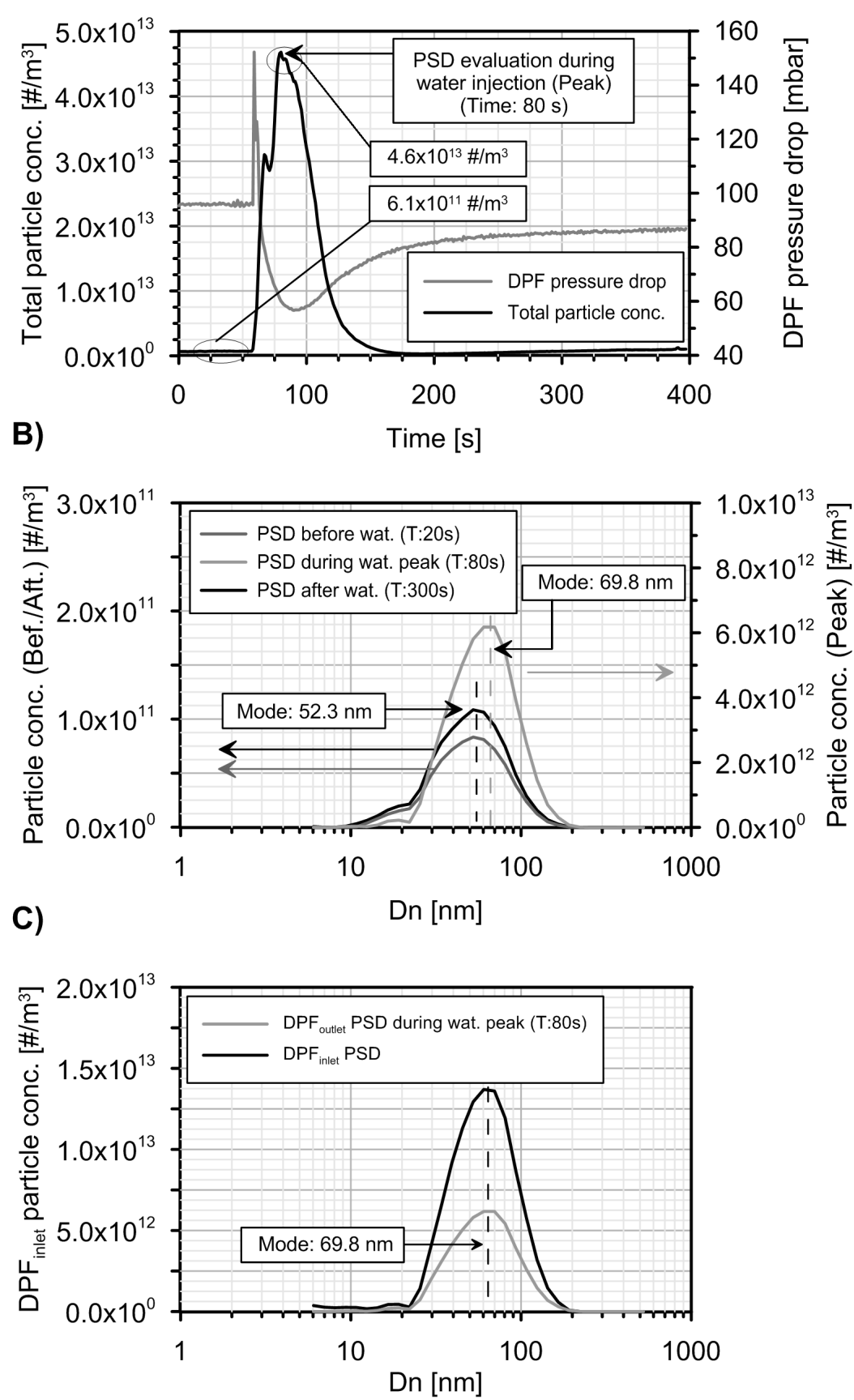

Figure 8: Particle number concentration evolution during a pre-DPF water injection event. A) Total particle number concentration evolution. B) Tailpipe particle size distribution evaluated before, during and after the pre-DPF water injection event. C) Raw particle size distribution at the inlet of the DPF compared to tailpipe particle size distribution during pre-DPF water injection event (Peak). 


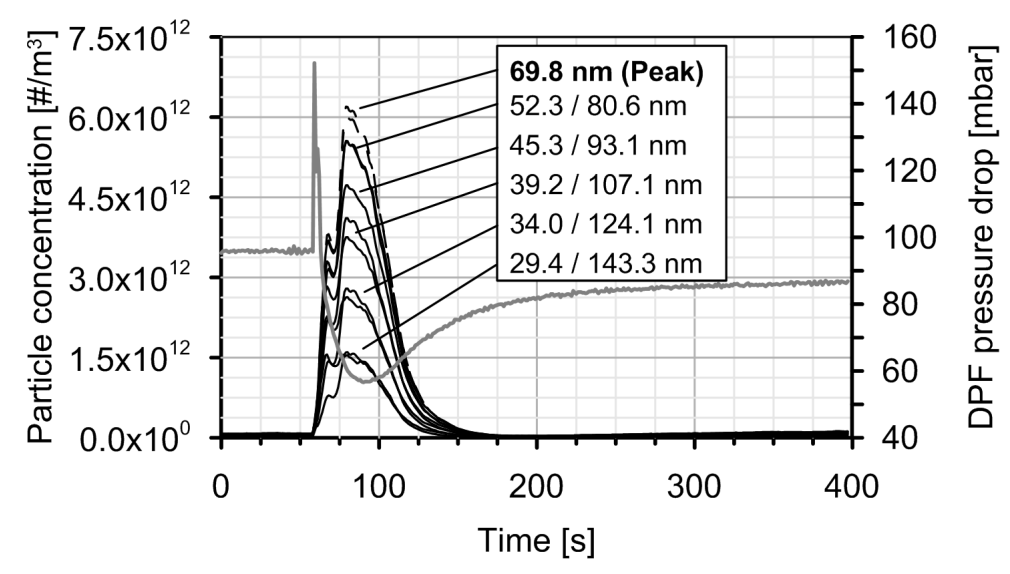

Figure 9: Evolution of the tailpipe particle number concentration as a function of the particle diameter during a pre-DPF water injection event.
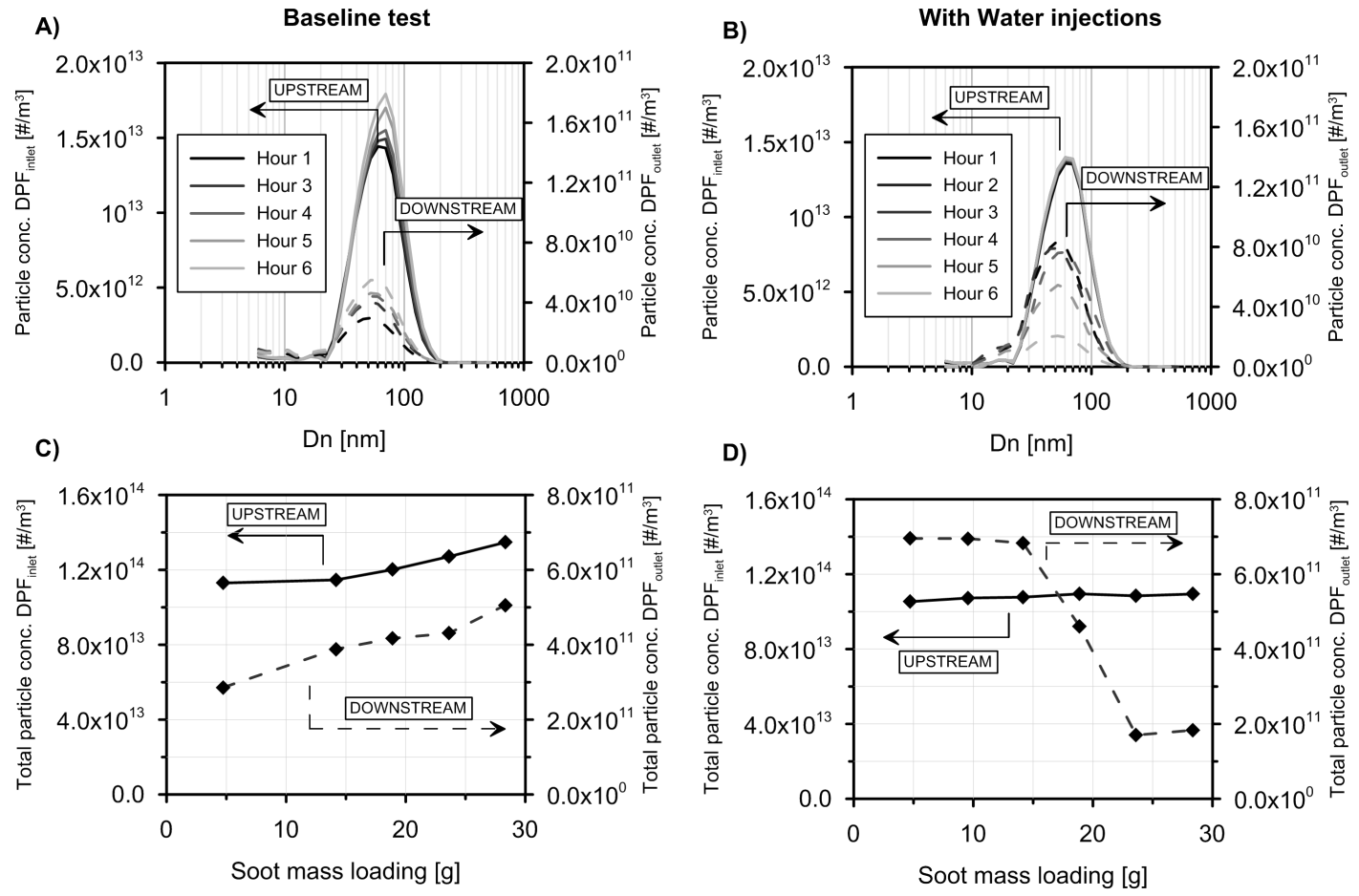

Figure 10: Particle size distribution and total particle concentration during DPF loading test. A) Raw and tailpipe PSD during the baseline DPF loading test. B) Raw and tailpipe PSD during the DPF loading test with use pre-DPF water injection technique. C) Raw and tailpipe total particle concentration during the baseline DPF loading test. D) Raw and tailpipe total particle concentration during the DPF loading test with use pre-DPF water injection technique. 
A)

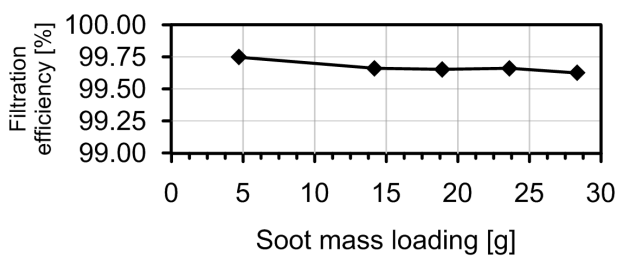

C)

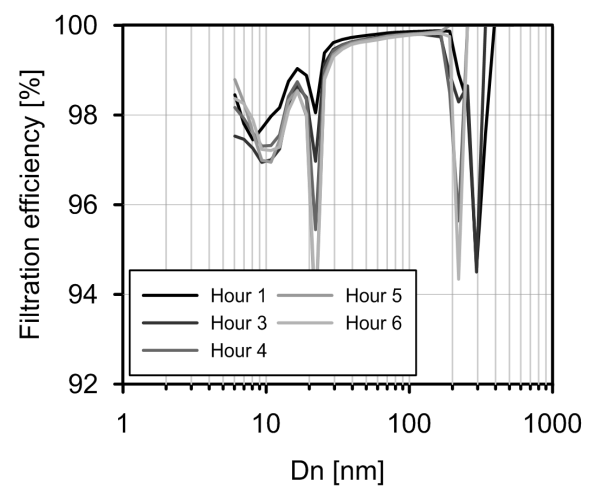

B)

With Water injections

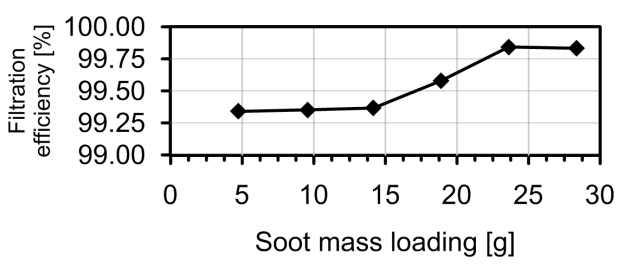

D)

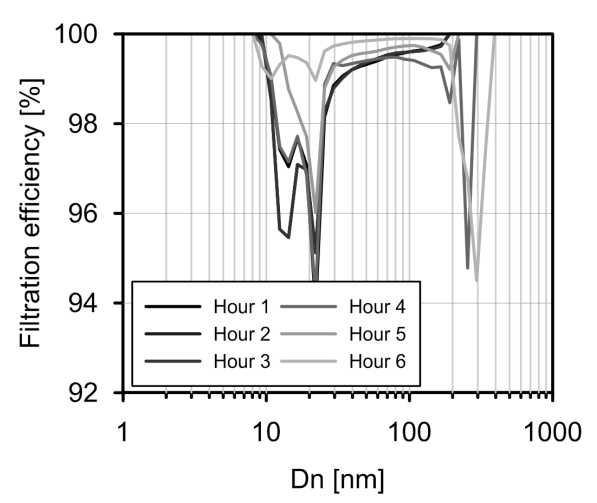

Figure 11: DPF filtration efficiency during DPF loading test. A) Overall DPF filtration efficiency during the baseline DPF loading test. B) Overall DPF filtration efficiency during the DPF loading test with use pre-DPF water injection technique. C) DPF filtration efficiency as a function of the particle size during the baseline DPF loading test. D) DPF filtration efficiency as a function of the particle size during the DPF loading test with use pre-DPF water injection technique. 


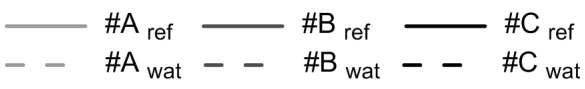

A)

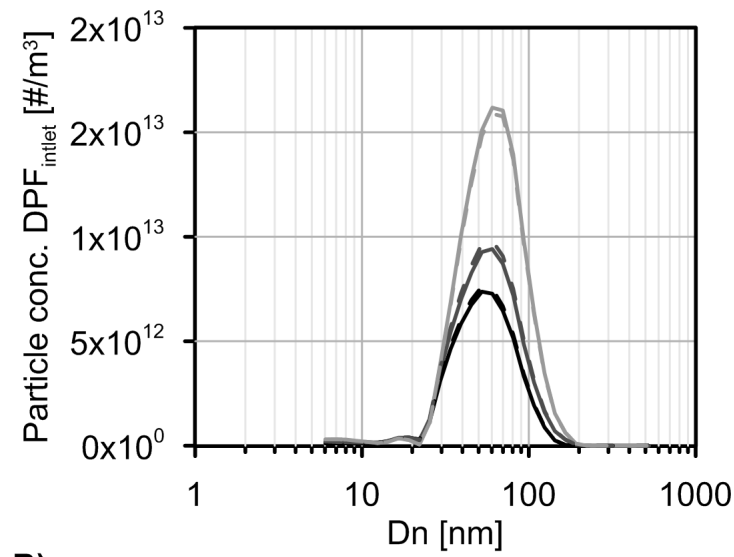

B)

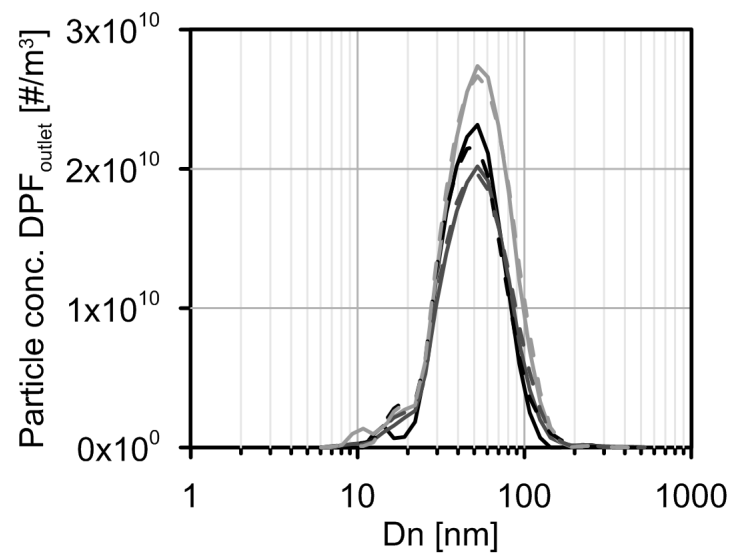

C)

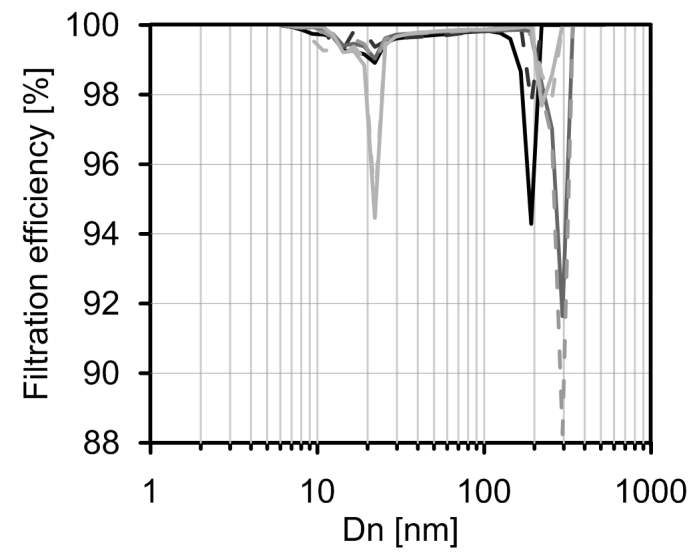

Figure 12: Comparison in raw and tailpipe particle number concentration and DPF filtration efficiency as a function of the particle size during the test of the steady-state operating conditions at low load. 
A1)

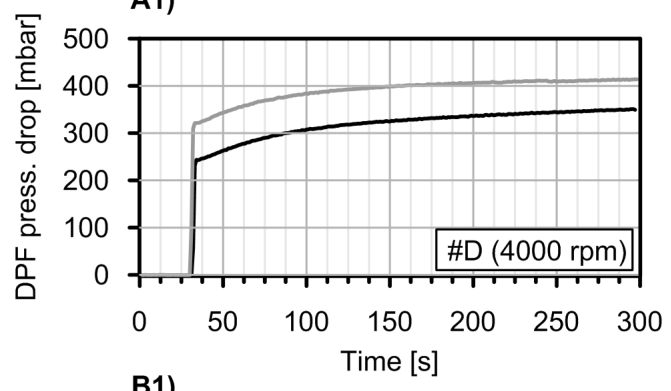

B1)

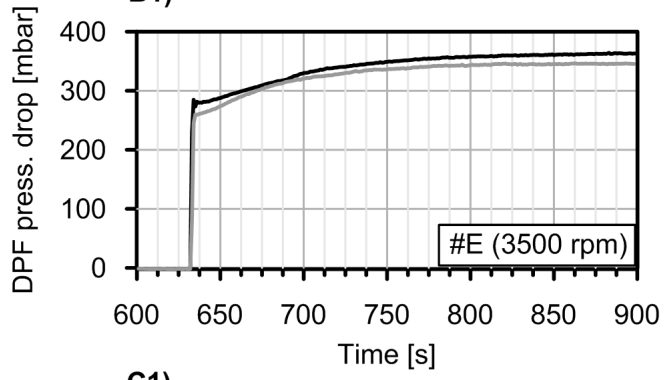

C1)

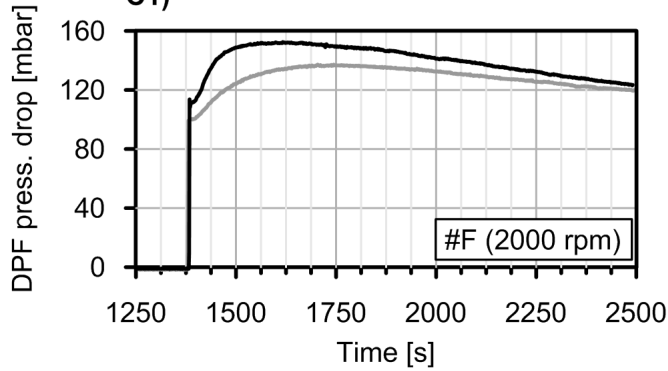

A2)

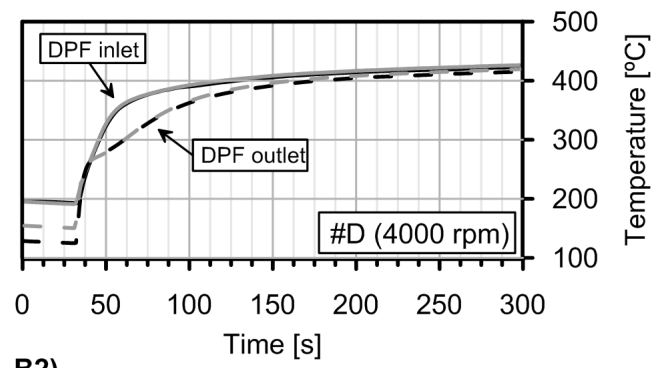

B2)

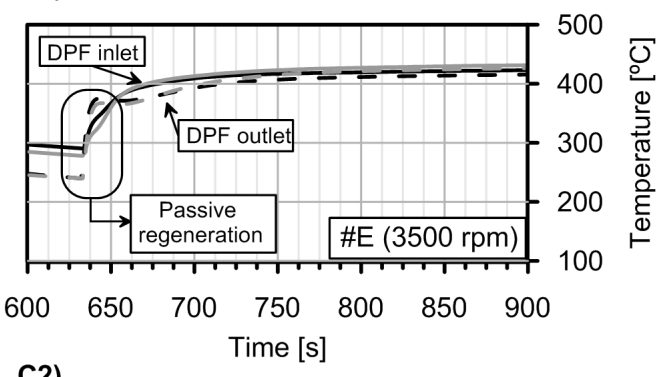

C2)

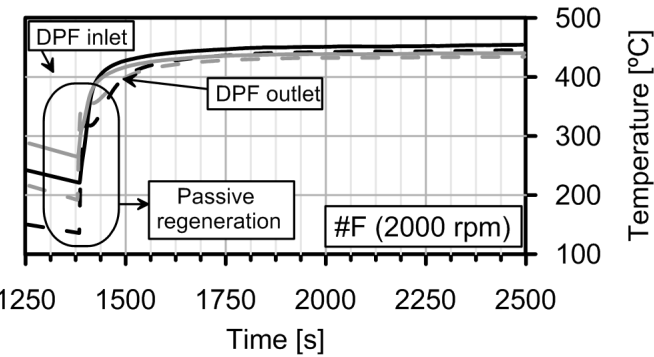

Figure 13: DPF pressure drop and gas temperature during the test of the steady-state operating conditions at high load comparing between baseline test and use of the pre-DPF water injection technique. 


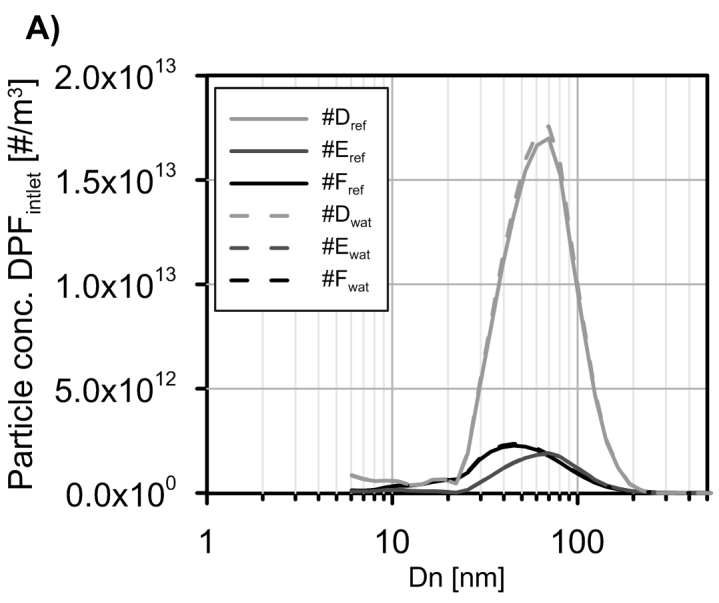

B)

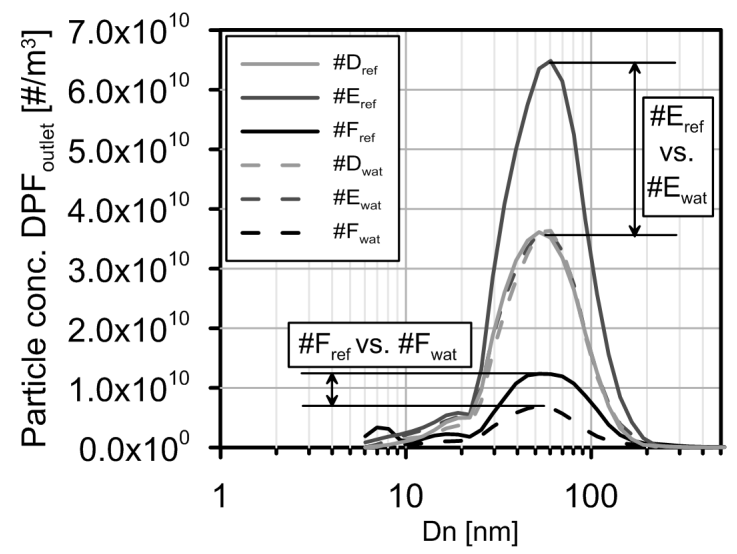

Figure 14: Raw and tailpipe particle size distribution during the test of the steady-state operating conditions at high load comparing between baseline test and use of the pre-DPF water injection technique. 